\title{
Endoscopic Vein Harvesting for Coronary Artery Bypass Grafting is Safe and Reduces Postoperative Resource Consumption
}

\section{Lars Oddershede ${ }^{1,2}$ and Jan Jesper Andreasen ${ }^{1 *}$}

${ }^{1}$ Departments of Cardiothoracic Surgery and Clinical Medicine, Centre for Cardiovascular Research, Aalborg University Hospital, Denmark

${ }^{2}$ Danish Center for Healthcare Improvements, Faculty of Social Sciences and Faculty of Health Sciences, Aalborg University, Denmark

\begin{abstract}
Background: The greater saphenous vein is still frequently used as a conduit for coronary artery bypass grafting (CABG). Previously, veins were harvested through a single continuous skin incision, commonly referred to as open vein harvesting $(\mathrm{OVH})$, while endoscopic vein harvesting $(\mathrm{EVH})$ techniques have become increasingly popular. However, the postoperative consumption of healthcare resources remains uncertain. Therefore, the present study performed a systematic review, with meta-analysis, of outcomes relating to consumption of healthcare resources and clinical effectiveness following EVH and OVH for CABG.
\end{abstract}

Methods: A systematic search was performed in five databases. OVH was defined as the use of open harvesting techniques using a single continuous incision, and all studies comparing EVH to OVH for CABG were eligible.

Results: EVH was associated with increased duration of surgery, no difference in the length of stay in intensive care units, a reduced total length of stay in hospital, a reduced need for antibiotic treatment for leg wound infections, a reduced need for follow-up visit(s) at general practitioners/out-patient clinics, a reduced need for visit(s) by the homecare nurses, a reduced need for revision(s) of the leg wound, a reduced need for readmission(s) related to leg wounds complications and no difference in repeat cardiac catheterization(s). Furthermore, EVH reduced pain intensity approximately five days postoperatively, but not 30 days postoperatively. EVH did not increase the occurrence of mid-term myocardial infarction, recurrence of chest pain, repeat revascularization and mid-term allcause mortality.

Conclusions: $\mathrm{EVH}$ provides safe clinical outcomes compared to OVH while reducing the short-term postoperative resource consumption. This article provides a formal synthesis of the available data on clinical effectiveness and consumption of healthcare resources following $\mathrm{EVH}$ and $\mathrm{OVH}$ for $\mathrm{CABG}$, hence enabling future investigation of the long-term cost-effectiveness of methods.

Keywords: Venous grafts; Endoscopy/endoscopic procedures; Health economics; Wound infection

\section{Introduction}

Most patients suffering from multi-vessel coronary artery disease should be treated with coronary artery bypass grafting (CABG) and although the use of arterial conduits was increasing, the greater saphenous vein is still frequently used as a conduit [1]. Previously, the harvesting process involved an open vein harvesting $(\mathrm{OVH})$ technique with a single continuous skin incision but today the majority is harvested using an endoscopic vein harvesting $(\mathrm{EVH})$ technique, as it reduces leg wound morbidity [2-4]. Several meta-analyses have been conducted to compare $\mathrm{OVH}$ techniques to minimally invasive vein harvesting techniques, yet none have actually compared $\mathrm{OVH}$ using a single continuous skin incision to EVH using total endoscopic equipment [413]. Moreover, recent meta-analyses did not include several outcomes relevant to the postoperative consumption of healthcare resources that could provide essential information for the estimation of EVH's costeffectiveness compared to $\mathrm{OVH}$ which is essential to make an informed decision about vein harvesting method $[14,15]$. Therefore, the present study performed a systematic review with meta-analysis of outcomes relating to resource consumption and clinical effectiveness following $\mathrm{EVH}$ and $\mathrm{OVH}$ with a single continuous skin incision.

\section{Materials and Methods}

\section{Search strategy and inclusion criteria}

In May 2014, we performed a systematic search in the following databases: Cochrane, Embase, Pubmed, Scopus, and Web of
Knowledge. In addition to the systematic search, a number of abstracts were identified thru secondary referencing. All studies comparing EVH to $\mathrm{OVH}$ for $\mathrm{CABG}$ were eligible, i.e. full articles, abstracts and posters were all included. OVH was defined as the use of open harvesting techniques using a single continuous incision, i.e. studies using bridging techniques were excluded. EVH was defined as: the VasoView system (Maquet, Wayne, NJ, USA), the ENDOPATH system (Ethicon Endosurgery, Cincinnati, OH, USA), the Clearglide Endoscopic Vessel Harvesting System (CardioVation, Ethicon Inc. Johnson \& Johnson, Somervill, NJ, USA), the Karl Storz Endoskope (Karl Storz, Tuttlingen, Germany), the VirtuoSaph system (Terumo Cardiovascular Corp., Ann Arbor, MI, USA), the EndoSaph Vein Harvest system (Unites States Surgical, Tyco Healthcare, Norwalk, CT, USA), a mixture of above mentioned, or if primary author's stated EVH was used although the system was not defined. Our search was not limited by language but in one case the inclusion was limited by language. Corresponding

*Corresponding author: Jan Jesper Andreasen, Departments of Cardiothoracic Surgery and Clinical Medicine, Centre for Cardiovascular Research, Aalborg University Hospital, Hobrovej 18-22, DK-9000 Aalborg, Denmark, Tel: +45 97664651; E-mail: jja@rn.dk

Received July 28, 2014; Accepted August 27, 2014; Published September 03 2014

Citation: Oddershede L, Andreasen JJ (2014) Endoscopic Vein Harvesting for Coronary Artery Bypass Grafting is Safe and Reduces Postoperative Resource Consumption. J Cardiovasc Dis Diagn 2: 171. doi:10.4172/2329-9517.1000171

Copyright: $\odot 2014$ Oddershede L, et al. This is an open-access article distributed under the terms of the Creative Commons Attribution License, which permits unrestricted use, distribution, and reproduction in any medium, provided the original author and source are credited. 
authors' of original studies were contacted if it was expected that they might be able to provide additional information. In cases where the study populations were reused, the study with the largest sample size and the longest follow-up was utilized.

The quality of the included trials was assessed by a single author (LO), using the Downs and Black Checklist for both randomized controlled trials and observational trials [16]. Like other reviews, we revised item 27 from the original Downs and Black Checklist $[17,18]$. We awarded one point if a sample size calculation had been performed and sufficient numbers were included. In the revised version, scores may range from 0 to 28 and high scores imply high quality. A detailed description of the scores given is provided in supplementary file 2 .

\section{Study outcomes}

The included papers were reviewed for 16 outcomes which potentially affects the costs and effectiveness of treatments. These were: (1) leg wound infection (LWI), (2) pain at postoperative day five, (3) pain at postoperative day $30,(4)$ recurrence of chest pain, (5) repeat revascularization, (6) mid-term myocardial infarction (MI), (7) midterm all-cause mortality, (8) total duration of surgery, (9) length of stay in intensive care unit (ICU), (10) total length of hospital stay, (11) use of antibiotics, (12) visit to physician, (13) visit by homecare nurse, (14) revision of leg wound, (15) readmission for leg wound complication, and (16) repeat cardiac catheterization. The definitions applied to each of the outcomes can be found in the supplementary file 3. Outcomes were retrieved from the included studies by a single author (LO).

\section{Statistical analyses}

Individual trials were pooled to perform a statistical comparison of OVH versus EVH. The $\mathrm{I}^{2}$ statistics were used to test for significant heterogeneity between studies [19]. Significant heterogeneity was defined as $\mathrm{I}^{2} \geq 50 \%$. The overall effect was calculated using fixed effects models in the absence of heterogeneity and random effects in the presence of heterogeneity.

The choice of statistical methods for comparing the pooled outcomes accounted for the fact that the outcome measures should be usable in a health economic evaluation. Categorical outcome variables were combined by calculating the log odds ratio (OR) if all studies presented the raw event counts. For some categorical outcome variables, the included studies reported either hazard ratios or raw event counts. For these outcomes the adjusted hazard ratio was extracted where possible, otherwise the rate ratios (RR) were calculated from the raw event counts. These were combined using the log RRs. A continuity correction of 0.5 was applied in studies reporting zero event count in one group. Zero-total event studies were excluded in all comparisons of categorical outcomes [20]. Continuous outcome variables were compared using weighted mean difference (WMD). Publication bias was assessed by visual inspection of funnel plots and by testing for small-studies effect using Eggers regression statistic. P-values $<0.05$ were considered statistically significant. The $95 \%$ confidence intervals (CIs) were reported rather than the p-values. All statistical analyses were performed in Stata version 12.1 (StataCorp, College Station, Texas, USA).

\section{Results}

A total of 2,780 abstracts were identified. Duplicates were removed and 1,420 abstracts were assessed for inclusion. 107 articles were selected for full text assessment and non-suitable articles were removed. A total of 47 articles were included in our study (Figure 1). A list of screened and excluded studies is available upon request. The characteristics of the studies included and the pooled baseline demographics are shown in Tables 1 and 2, respectively. The quality of the studies ranged from 10 to 24 (Scale $0-28$ ). The summary statistics are presented in Table 3 while forest plots and funnel plots related to each outcome are supplied in supplementary file 4 and 5, respectively. Unless stated otherwise, no publication bias was observed.

\section{Outcomes mainly related to resource consumption}

Fourteen studies (5 randomized controlled trials (RCTs) and 9 non-randomized controlled trials (nRCTs)) were identified for the comparison of total duration of surgery. Three studies were excluded as they did not present mean \pm standard deviation. Analysis of the remaining studies showed that EVH significantly increase surgery time (WMD 15.02, 95\% CI 3.07 to 26.97).

Five studies ( 3 RCTs and 2 nRCTs) were identified for the comparison of length of stay in ICU. A single study was excluded as it did not present mean \pm standard deviation. Analysis of the remaining four showed no difference in length of stay in ICU (WMD 0.05, 95\% CI -0.22 to 0.31 ). Sixteen studies ( 9 RCTs and 7 nRCTs) were identified for the analysis of total length of stay in hospital. From fifteen of these studies mean \pm standard deviation could be obtained and these were analyzed. Although no difference was observed in the length of stay in ICU, the total length of stay was significantly reduced for EVH patients (WMD-0.54, 95\% CI-100 to -0.09). Funnel plots showed some evidence of publication bias and this was confirmed by Egger's

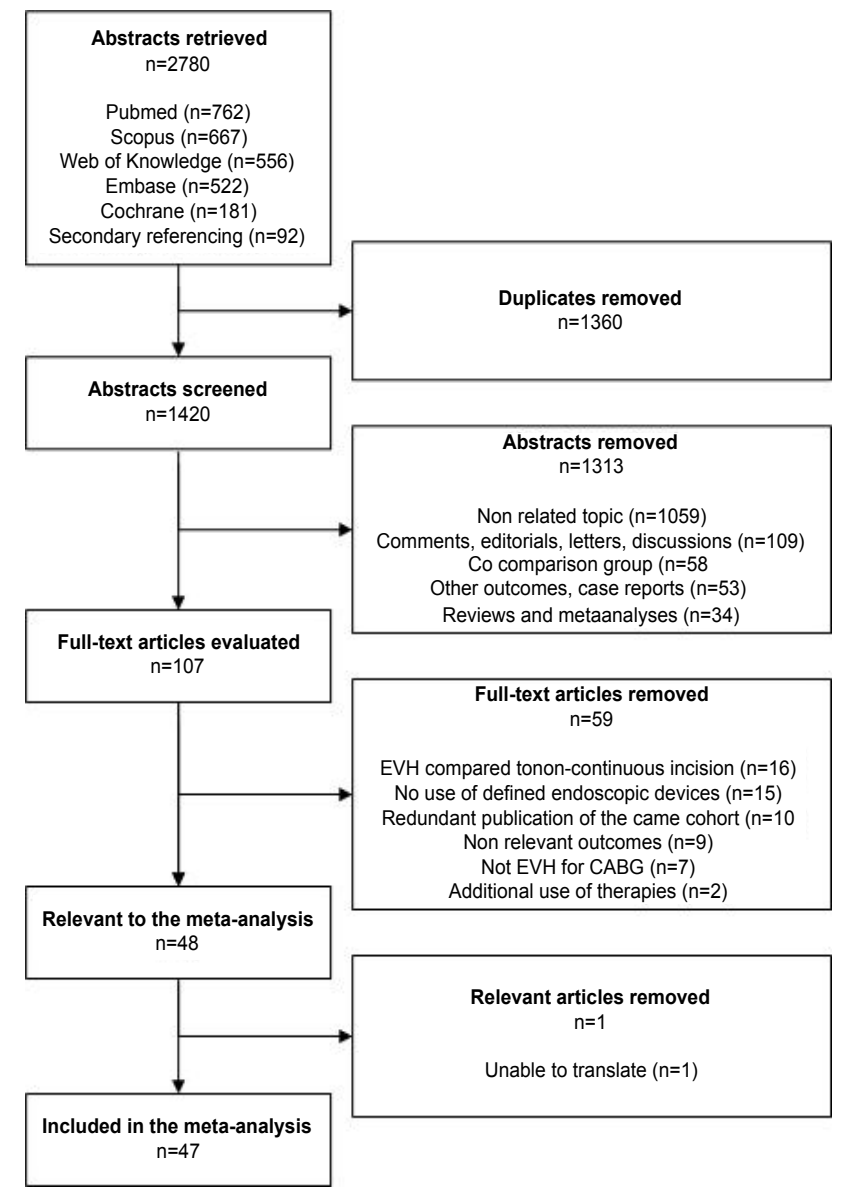

Figure 1: Search results and review process. 
Citation: Oddershede L, Andreasen JJ (2014) Endoscopic Vein Harvesting for Coronary Artery Bypass Grafting is Safe and Reduces Postoperative Resource Consumption. J Cardiovasc Dis Diagn 2: 171. doi:10.4172/2329-9517.1000171

Page 3 of 7

\begin{tabular}{|c|c|c|c|c|c|c|c|}
\hline First author's last name & Year & Design & $\begin{array}{l}\text { Downs and Black Score } \\
(\max 28)\end{array}$ & EVH device & EVH sample (n) & OVH sample $(n)$ & Outcomes available \\
\hline Ad, et al.[24] & 2011 & $\mathrm{R}$ & 16 & VV & 1734 & 254 & $1,4,5,6,7,9,10,14,15,16$ \\
\hline Allen, et al.[25] & 1998 & RCT & 18 & $E$ & 51 & 58 & $2,3,10,14$ \\
\hline Allen, et al. [26] & 2000 & $\mathrm{R}$ & 16 & $E$ & 276 & 643 & $1,11,12,13,15$ \\
\hline Allen, et al.[27] & 2003 & RCT & 17 & $E$ & 51 & 58 & 16 \\
\hline Andreas, et al.[28] & 2013 & $\mathrm{R}$ & 18 & VV & 262 & 623 & $1,7,10,14$ \\
\hline Andreasen, et al. [29] & 2008 & RCT & 24 & VV & 66 & 63 & $1,2,3,4,8,10,11,12,13,14,15,16$ \\
\hline Au, et al. [30] & 2008 & RCT & 22 & VS & 54 & 60 & $1,2,3,11,14,15$ \\
\hline Bitondo, et al. [31] & 2002 & PNRT & 15 & VV & 154 & 106 & $1,11,13,14,15$ \\
\hline Bonde, et al. [32] & 2004 & RCT & 18 & C & 52 & 56 & $1,2,4,7,8,11,15$ \\
\hline Brat, et al. [33] & 2013 & RCT & 17 & VS & 50 & 50 & 1 \\
\hline Carpino, et al. [34] & 2000 & RCT & 19 & VV & 66 & 66 & $1,4,10,11,15$ \\
\hline Chou, et al. [35] & 2009 & PNRT & 17 & VV & 270 & 78 & $1,2,3,6,7,8,10,14$ \\
\hline Cisowski, et al. [36] & 2000 & RCT & 16 & $E+V V$ & 30 & 15 & 1,8 \\
\hline Coppoolse, et al. [37] & 1999 & PNRT & 10 & KSE & 300 & 300 & $1,8,14$ \\
\hline Crouch, et al. [38] & 1999 & $\mathrm{R}$ & 20 & VV & 180 & 388 & $1,10,11,14,15$ \\
\hline Dacey, et al. [2] & 2011 & $\mathrm{R}$ & 20 & $\mathrm{n} / \mathrm{a}$ & 4,480 & 4,062 & $1,5,7,14$ \\
\hline Dangel, et al. [39] & 1998 & PNRT & 11 & KSE & 13 & 46 & 1,14 \\
\hline Davis, et al. [40] & 1998 & PNRT & 13 & $E$ & 110 & 99 & $1,2,3,8,10,12,15$ \\
\hline Fabricius, et al. [41] & 2000 & RCT & 17 & $\mathrm{n} / \mathrm{a}$ & 31 & 30 & $1,14,15$ \\
\hline Felisky, et al. [42] & 2002 & $\mathrm{R}$ & 15 & VV & 340 & 380 & $1,5,8,11,14,15,16$ \\
\hline Folliguet, et al. [43] & 1999 & RCT & 18 & $E+V V$ & 60 & 60 & $1,10,11,13,14,15,16$ \\
\hline Galbraith, et al. [44] & 2000 & $\mathrm{R}$ & 14 & ES & 77 & 135 & $1,8,10,15$ \\
\hline Grant, et al. [45] & 2011 & PNRT & 16 & VV & 533 & 2,132 & 7,14 \\
\hline Hassan, et al. [46] & 2013 & $\mathrm{R}$ & 9 & $\mathrm{n} / \mathrm{a}$ & 542 & 1221 & 1 \\
\hline Hayward, et al. [47] & 1999 & RCT & 20 & $E$ & 50 & 50 & 1,10 \\
\hline Ikram, et al. [48] & 2010 & PNRT & 18 & VV & 99 & 236 & $1,2,8,10,11,14,15$ \\
\hline Inderbitzin, et al. [49] & 2012 & PNRT & 14 & n/a & 973 & 278 & 1 \\
\hline Isgro, et al. [50] & 1999 & RCT & 13 & VV & 103 & 105 & 1,8 \\
\hline Javidi, et al. [51] & 2008 & RCT & 17 & C & 75 & 75 & 1,15 \\
\hline Kan, et al. [52] & 1999 & PNRT & 16 & $E$ & 60 & 59 & $1,8,9,11,14$ \\
\hline Kiaii, et al. [53] & 2002 & RCT & 20 & $E+K S E$ & 72 & 72 & $1,2,3,8,9,10,11,12,13,15$ \\
\hline Kirmani, et al. [54] & 2010 & $\mathrm{R}$ & 13 & VV & 89 & 182 & $1,2,4,5,7,16$ \\
\hline Krishnamoorthy, et al. [55] & 2012 & RCT & 22 & VV & 50 & 50 & $1,11,12,13$ \\
\hline Li, et al. [56] & 1998 & $\mathrm{R}$ & 14 & $E$ & 50 & 106 & 1,10 \\
\hline Lopes, et al. [57] & 2009 & $\mathrm{R}$ & 17 & n/a & 1,753 & 1,247 & $5,6,7$ \\
\hline Morris, et al. [58] & 1998 & PNRT & 15 & VV & 27 & 24 & 1,2 \\
\hline Nahata, et al. [59] & 1998 & $\mathrm{R}$ & 10 & n/a & 300 & 300 & $1,11,14,15$ \\
\hline Pagni, et al. [60] & 1998 & PNRT & 16 & $E$ & 50 & 40 & $1,2,11,14,15$ \\
\hline Perrault, et al. [61] & 2004 & RCT & 18 & VV & 17 & 15 & $1,9,10,14$ \\
\hline Puskas, et al. [62] & 1999 & RCT & 18 & $E$ & 47 & 50 & $1,9,10,11,14,15$ \\
\hline Schurr, et al. [63] & 2002 & RCT & 17 & VV & 80 & 60 & $1,10,11,14,15$ \\
\hline Terrini, et al. [64] & 2000 & $\mathrm{R}$ & 10 & $E S+V V$ & 41 & 20 & $1,8,14$ \\
\hline Wang, et al. [65] & 2011 & RCT & 18 & VV & 20 & 20 & $1,4,5,14$ \\
\hline Williams, et al. [3] & 2012 & $\mathrm{R}$ & 21 & $n / a$ & 122,899 & 112,495 & 1,7 \\
\hline Yadav, et al. [66] & 2012 & $\mathrm{R}$ & 10 & n/a & 402 & 289 & $1,4,7,8,16$ \\
\hline Yun, et al. [67] & 2005 & RCT & 21 & VV & 100 & 100 & $1,4,5,14$ \\
\hline Zenati, et al. [68] & 2011 & PNRT & 19 & n/a & 564 & 907 & $5,6,7,14$ \\
\hline
\end{tabular}

C: The Clearglide Endoscopic Vessel Harvesting System (CardioVation, Ethicon Inc. Johnson \& Johnson, Somervill, NJ, USA); E: The Endopath system (Ethicon Endosurgery, Cincinnati, OH, USA); ES: The EndoSaph Vein Harvest system (Unites States Surgical, Tyco Healthcare, Norwalk, CT, USA); KSE: The Karl Storz Endoskope (Karl Storz, Tuttlingen, Germany); n/a: Not Available; PNRT: Prospective Non-Randomized Trial; R: Retrospective; RCT: Randomized Controlled Trial; VS: The Virtuosaph System (Terumo Cardiovascular Corp., Ann Arbor, MI, USA); VV: The VasoView system (Maquet, Wayne, NJ, USA)

Table 1: Descriptive information of included studies.

\begin{tabular}{|l|c|c|c|}
\hline Variable & EVH (n=137,601) & OVH (n=127,647) & Availability (percentage of patients) \\
\hline Age (years), mean & 64.1 & 65.3 & $93.9 \%$ \\
\hline Male, \% & $79.2 \%$ & $75.6 \%$ & $98.4 \%$ \\
\hline Diabetes, \% & $32.2 \%$ & $30.7 \%$ & $98.3 \%$ \\
\hline Smoking, \% & $44.1 \%$ & $44.4 \%$ & $92.7 \%$ \\
\hline Body mass index $\left(\mathrm{kg} / \mathrm{m}^{2}\right)$, mean & 27.5 & 27.5 & $91.9 \%$ \\
\hline Obesity a, $\%$ & $24.5 \%$ & $23.7 \%$ & $4.1 \%$ \\
\hline EUROscore, mean & 4.1 & 4.5 & $1.3 \%$ \\
\hline
\end{tabular}

EUROscore: European system for cardiac operative risk evaluation; EVH: Endoscopic Vein Harvesting; OVH: Open Vein Harvesting; ${ }^{\text {Obesity }}$ was defined as a BMI>30 kg/m² Table 2: Pooled baseline characteristics. 


\begin{tabular}{|c|c|c|c|c|}
\hline Outcome & Studies analyzed (RCT/nRCT) & Sample size & Summary measure & $\mathbf{I}^{2}$ \\
\hline \multicolumn{5}{|c|}{ Odds ratios $(95 \% \mathrm{Cl})$} \\
\hline Leg wound infection & $17 / 24$ & 258,072 & $0.22(0.15$ to 0.32$)$ & $83.1 \%$ \\
\hline Use of antibiotics & $8 / 8$ & 4,563 & $0.25(0.19$ to 0.34$)$ & $0 \%$ \\
\hline Visit to physician & $3 / 2$ & 1,501 & $0.29(0.17$ to 0.48$)$ & $0 \%$ \\
\hline Visit by homecare nurse & $4 / 2$ & 1,672 & $0.09(0.04$ to 0.21$)$ & $0 \%$ \\
\hline Revision of leg wound & $8 / 15$ & 20,199 & $0.44(0.26$ to 0.74$)$ & $69.6 \%$ \\
\hline Readmission for leg wound complication & $6 / 10$ & 6,609 & $0.62(0.45$ to 0.85$)$ & $11.0 \%$ \\
\hline Recurrence of chest pain & $2 / 2$ & 2,567 & $0.98(0.62$ to 1.55$)$ & $0 \%$ \\
\hline Repeat cardiac catheterization & $1 / 3$ & 3,088 & $1.06(0.66$ to 1.68$)$ & $0 \%$ \\
\hline Mid-term myocardial infarction & $0 / 4$ & 6,807 & $1.13(0.73$ to 1.74$)$ & $0 \%$ \\
\hline \multicolumn{5}{|c|}{ Weighted mean difference $(95 \% \mathrm{Cl})$} \\
\hline Total duration of surgery (minutes) & $4 / 7$ & 2,666 & 15.02 (3.07 to 26.97$)$ & $91.1 \%$ \\
\hline Pain at postoperative day 5 (cm on a VAS) & $5 / 5$ & 1,857 & $-1.48(-2.45$ to -0.50$)$ & $98.7 \%$ \\
\hline Pain at postoperative day 30 ( $\mathrm{cm}$ on a VAS) & $4 / 2$ & 1,053 & $-0.28(-0.60$ to 0.04$)$ & $84.0 \%$ \\
\hline Length of stay in ICU (days) & $2 / 2$ & 2,283 & $0.05(-0.22$ to 0.31$)$ & $0 \%$ \\
\hline Total length of hospital stay (days) & $8 / 7$ & 5,451 & $-0.54(-1.00$ to -0.09$)$ & $56.3 \%$ \\
\hline \multicolumn{5}{|c|}{ Rate ratio $(95 \% \mathrm{Cl})$} \\
\hline Repeat revascularization & $1 / 6$ & 16,162 & $1.20(1.02$ to 1.42$)$ & $0 \%$ \\
\hline Mid-term all-cause mortality & $0 / 10$ & 255,329 & $0.92(0.77$ to 1.11$)$ & $58.9 \%$ \\
\hline
\end{tabular}

Cl: Confidence Interval; ICU: Intensive Care Unit; nRCT: Non-Randomized Controlled Trial; RCT: Randomized Controlled Trial; VAS: Visual Analogue Scale

Table 3: Summary of results for each outcome ordered by the summary measure.

regression statistic.

Seventeen studies (9 RCTs and $8 \mathrm{nRCTs}$ ) recorded the number of patients receiving antibiotic treatment for their LWI. One RCT was excluded as it reported zero-total events. Analysis of the remaining 16 studies showed that EVH significantly reduced the use of antibiotics (OR 0.25, 95\% CI 0.19 to 0.34 ).

Five studies ( 3 RCTs and 2 nRCTs) recorded the number of patients in need of follow-up visit at their GP or at the out-patient clinic. Analysis showed that EVH significantly reduced this need (OR $0.29,95 \%$ CI 0.17 to 0.48 ). Likewise, six studies (4 RCTs and 2 nRCTs) were included in the analysis of need for visits by the homecare nurse which EVH also significantly reduces (OR $0.09,95 \%$ CI 0.04 to 0.21 ).

Twenty-six studies (10 RCTs and $16 \mathrm{nRCTs}$ ) recorded if revision of the leg wound was needed. Three of these studies (2 RCTs and 1 nRCT) were excluded as they reported zero-total events. Analysis of the remaining studies showed a significant reduction in revision for the EVH group (OR 0.44, 95\% CI 0.26 to 0.74 ). Funnel plots showed evidence of publication bias which was confirmed by Egger's regression statistic.

Twenty studies (10 RCTs and $10 \mathrm{nRCTs}$ ) reported the number of patients readmitted for complications related to their leg wound. Four RCTs reported zero-total events and were excluded and the analysis of the remaining studies showed that $\mathrm{EVH}$ significantly reduced the number of readmissions (OR $0.62,95 \%$ CI 0.45 to 0.85 ).

Seven studies (3 RCTs and $4 \mathrm{nRCTs}$ ) reported the number of repeat cardiac catheterizations. Three out of these seven studies reported zerototal event counts and were excluded. Analysis of the remaining four studies (1 RCT and $3 \mathrm{nRCTs}$ ) showed no difference between treatments (OR $1.06,95 \%$ CI 0.66 to 1.68 ).

\section{Clinical outcomes}

Forty-two studies (18 RCTs and 24 nRCTs) reported LWI. One RCT had zero-total events and was excluded. Analysis of the remaining 41 studies showed that EVH significantly reduced the odds of LWI
(OR $0.22,95 \%$ CI 0.15 to 0.32 ). The corresponding funnel plot showed evidence of publication bias and Egger's regression statistic was significant.

Eleven studies (5 RCTs and 6 nRCTs) investigated pain intensity measured on a $10 \mathrm{~cm}$ visual analogue scale (VAS) approximately five days postoperatively. One study was excluded as the standard deviation of the mean VAS scores was not reported. Analysis of the remaining ten studies showed that EVH was superior to OVH (WMD -1.48, 95\% CI -2.45 to -0.50 ). Likewise, six studies (4 RCTs and $2 \mathrm{nRCTs}$ ) investigated pain intensity approximately 30 days postoperatively. Although EVH showed a tendency towards a reduction in the pain intensity, the difference was not statistically significant at approximately 30 days postoperatively (WMD $-0.28,95 \%$ CI -0.60 to 0.04 ).

Eight studies (5 RCTs and 3 nRCTs) investigated the recurrence of chest pain. Four of these studies were excluded due to zero-total events and analysis of the remaining four studies (2 RCTs and 2 nRCTs) showed no difference in the recurrence of chest pain (OR 0.98, 95\% CI 0.62 to 1.55$)$.

Eight studies (2 RCT and 6 nRCTs) reported hazard ratios or raw event counts for repeat revascularization. The seven studies (1 RCT and $6 \mathrm{nRCTs}$ ) which reported non-zero-total events were combined using RR as the summary measure. Analysis showed that EVH patients had a statistically significant increased rate of repeat revascularization (RR $1.20,95 \%$ CI 1.02 to 1.42 ). A sensitivity analysis of repeat revascularization was conducted using studies with a Down and Black score of 20 or more. Two studies (1 RCT and 1 nRCT) were included in this sensitivity analysis and in this analysis EVH was not associated with an increased risk of repeat revascularization (RR 1.28, 95\% CI 0.95 to 1.71$)$.

Four studies (4 nRCTs) reported occurrence of MIs with a minimum follow-up of 12 months. These studies were included in the analysis of mid-term MI which showed no difference between treatments (OR 1.13, 95\% CI 0.73 to 1.74 ). 
Eleven studies (1 RCT and 10 nRCTs) supplied hazard ratios or raw event counts regarding all-cause mortality with a follow-up above 12 months. The RCT had zero-total events and was excluded. The remaining ten studies were combined using RR as the summary measure. No difference in mid-term all-cause mortality was found (RR $0.92,95 \%$ CI 0.77 to 1.11 ).

\section{Discussion}

Compared to $\mathrm{OVH}, \mathrm{EVH}$ was shown to reduce leg wound morbidity in the short-term postoperative course. The mid-term clinical outcomes did not appear different between groups. EVH was not associated with an increased risk of repeat revascularization when analyzing the studies with the highest quality scores. This proves that EVH may be used without compromising safety. Although EVH appeared to be a slightly more time consuming technique, the postoperative resource consumption was reduced. As such, EVH will reduce costs related to hospital stay, surgical revisions, follow-up visits, and antibiotics, compared to OVH. It should be noted that this is not the same as concluding that $\mathrm{EVH}$ is cost-saving compared to $\mathrm{OVH}$.

Several other studies have conducted systematic reviews, with metaanalyses, of outcomes following minimally invasive vein harvesting techniques compared to open vein harvesting techniques [4-13]. One main difference between the present study and the previous studies should be noted: the definition of the harvesting techniques plays a crucial role in the inclusion of studies. As an example, the present study applied the same definition of EVH as Deppe et al. [5] but defined the comparator differently. Deppe et al. defined the comparator, conventional vein harvesting, as open harvesting techniques with or without a continuous skin incision (i.e., bridging technique) or the use of any other kind of non-total endoscopic instrument, including the SaphLITE System (Teleflex Medical, Research Triangle Park, NC) or the VEGA system (B. Braun-Aesculap, Tuttlingen, Germany). The meta-analysis by Sastry et al. [4] applied the same definition as the present study for OVH, while EVH was defined differently. Sastry et al. considered the SaphLITE System, which was considered a conventional harvesting technique by Deppe et al., an endoscopic technique. These differences in the definitions of harvesting techniques, and outcomes for that matter, impede the comparison of our results to those of other meta-analyses. While point-estimates may differ slightly, the conclusions for clinical outcomes do not differ.

\section{Strengths and limitations}

While the present meta-analysis applied a more strict definition of $\mathrm{OVH}$ and $\mathrm{EVH}$ than previous meta-analyses it identified more relevant studies than any other met-analysis. As such, it provides a thorough comparison of OVH using a single continuous skin incision to EVH using total endoscopic equipment. However, a few limitations should be noted when interpreting the results. Firstly, none of the studies included were RCTs designed to test the long-term safety and effectiveness of EVH compared to OVH. Especially, no RCTs with a follow-up above 12 months could be included in the analysis of midterm MI and all-cause mortality. The need for further high-quality RCTs with a longer follow-up have been acknowledged by the clinical community and two studies are expected. The ESOS trial will report events of death, MI and recurrence of angina within two year following randomization for approximately 200 patients [21]. The REGROUP trial is expected to run for approximately 6.5 years and will report events of all-cause mortality, MI and repeat revascularization for roughly 1150 patients [22]. Before the results of these studies become available, the long-term safety of EVH should be interpreted with caution. Secondly, meta-analyses of non-RCT may be prone to biased results if the individual studies contain selection bias. While this could be handled be performing secondary analysis where non-RCT are not included, it was chosen not to do so in the present study. If non-RCT were excluded in a secondary analysis, several outcomes would have no information or information from one or two studies. Hence, metaanalysis might not be that relevant. Thirdly, meta-analyses of EVH vs. $\mathrm{OVH}$ have been criticized for lacking information about the quality of the saphenous vein and the experience of the surgeons performing the harvest [23]. A poor-quality vein conduit is going to have poor patency, regardless of which method was used. Nevertheless, meta-analysis remains the gold standard. The key should be to interpret the metaanalyses as the, current, best available evidence.

\section{Conclusion}

EVH increases the intraoperative resource consumption while it reduces the postoperative resource consumption. EVH provides a reduction in short-term leg wound related morbidity compared to $\mathrm{OVH}$ and the major clinical outcomes are similar for both groups. Whether this translates into EVH being cost-effective compared to $\mathrm{OVH}$ can only be evaluated in a rigorous cost-effectiveness analysis.

\section{Acknowledgement}

We thank Susanne Ellemose Oddershede, Master of Arts, and Alex Fomcenco, Master of Laws, for their linguistic assistance. Furthermore, we wish to thank all the authors who provided additional information for this manuscript.

\section{Funding Sources}

This work was funded by the Danish Center for Healthcare Improvements which is a public, noncommercial, research organization.

\section{References}

1. Task Force on Myocardial Revascularization of the European Society of Cardiology (ESC) and the European Association for Cardio-Thoracic Surgery (EACTS); European Association for Percutaneous Cardiovascular Interventions (EAPCI), Wijns W, Kolh P, Danchin N, Di Mario C, et al. (2010) Guidelines on myocardial revascularization. Eur Heart J 31: 2501-2555.

2. Dacey LJ, Braxton JH Jr, Kramer RS, Schmoker JD, Charlesworth DC, et al. (2011) Long-term outcomes of endoscopic vein harvesting after coronary artery bypass grafting. Circulation 123: 147-153.

3. Williams JB, Peterson ED, Brennan JM, Sedrakyan A, Tavris D, et al. (2012) Association between endoscopic vs open vein-graft harvesting and mortality, wound complications, and cardiovascular events in patients undergoing CABG surgery. JAMA 308: 475-484.

4. Sastry P, Rivinius R, Harvey R, Parker RA, Rahm AK, et al. (2013) The influence of endoscopic vein harvesting on outcomes after coronary bypass grafting: a meta-analysis of 267,525 patients. Eur J Cardiothorac Surg 44: 980-989.

5. Deppe AC, Liakopoulos OJ, Choi YH, Slottosch I, Kuhn EW, et al. (2013) Endoscopic vein harvesting for coronary artery bypass grafting: a systematic review with meta-analysis of 27,789 patients. J Surg Res 180: 114-124.

6. Cadwallader RA, Walsh SR, Cooper DG, Tang TY, Sadat U, et al. (2009) Great saphenous vein harvesting: a systematic review and meta-analysis of open versus endoscopic techniques. Vasc Endovascular Surg 43: 561-566.

7. Cheng D, Allen K, Cohn W, Connolly M, Edgerton J, et al. (2005) Endoscopic Vascular Harvest in Coronary Artery Bypass Grafting Surgery: A Meta-Analysis of Randomized Trials and Controlled Trials. Innovations (Phila) 1: 61-74.

8. Markar SR, Kutty R, Edmonds L, Sadat U, Nair S (2010) A meta-analysis of minimally invasive versus traditional open vein harvest technique for coronary artery bypass graft surgery. Interact Cardiovasc Thorac Surg 10: 266-270.

9. Reed JF 3rd (2008) Leg wound infections following greater saphenous vein harvesting: minimally invasive vein harvesting versus conventional vein harvesting. Int J Low Extrem Wounds 7: 210-219.

10. Athanasiou T, Aziz O, Al-Ruzzeh S, Philippidis P, Jones C, et al. (2004) Are wound healing disturbances and length of hospital stay reduced with minimally 
invasive vein harvest? A meta-analysis. Eur J Cardiothorac Surg 26: 10151026.

11. Zenati M, Biswas K, Shroyer LA, Quin J, Haime M, et al. (2012) Long-term patency of coronary artery bypass vein grafts harvested endoscopically: A meta-analysis. J Am Coll Cardiol 59: E1450.

12. Athanasiou T, Aziz O, Skapinakis P, Perunovic B, Hart J, et al. (2003) Leg wound infection after coronary artery bypass grafting: a meta-analysis comparing minimally invasive versus conventional vein harvesting. Ann Thorac Surg 76: 2141-2146.

13. Aziz O, Athanasiou T, Panesar SS, Massey-Patel R, Warren O, et al. (2005) Does minimally invasive vein harvesting technique affect the quality of the conduit for coronary revascularization? Ann Thorac Surg 80: 2407-2414.

14. García-Altés A, Peiró S (2011) A systematic review of cost-effectiveness evidence of endoscopic saphenous vein harvesting: is it efficient? Eur J Vasc Endovasc Surg 41: 831-836.

15. Drummond MF, Sculpher MJ, Torrance GW, O'Brien BJ, Stoddart GL (2005) Methods for the Economic Evaluation of Health Care Programmes. (3rd Edn.), Oxford University Press, New York.

16. Downs SH, Black N (1998) The feasibility of creating a checklist for the assessment of the methodological quality both of randomised and nonrandomised studies of health care interventions. J Epidemiol Community Health 52: 377-384.

17. Samoocha D, Bruinvels DJ, Elbers NA, Anema JR, van der Beek AJ (2010) Effectiveness of web-based interventions on patient empowerment: a systematic review and meta-analysis. J Med Internet Res 12: e23.

18. Kaminskyj A, Frazier M, Johnstone K, Gleberzon BJ (2010) Chiropractic care for patients with asthma: A systematic review of the literature. J Can Chiropr Assoc 54: 24-32.

19. Higgins JP, Thompson SG, Deeks JJ, Altman DG (2003) Measuring inconsistency in meta-analyses. BMJ 327: 557-560.

20. Whitehead A, Whitehead J (1991) A general parametric approach to the metaanalysis of randomized clinical trials. Stat Med 10: 1665-1677.

21. Campanella A, Bergamasco L, Macri L, Asioli S, Devotini R, et al. (2011) Endoscopic Saphenous harvesting with an Open CO2 System (ESOS) tria for coronary artery bypass grafting surgery: study protocol for a randomized controlled trial. Trials 12: 243

22. Zenati MA, Gaziano JM, Collins JF, Biswas K, Gabany JM, et al. (2014) Choice of vein-harvest technique for coronary artery bypass grafting: rationale and design of the REGROUP trial. Clin Cardiol 37: 325-330.

23. Chu D (2013) Endoscopic vein harvest or not? J Surg Res 185: 530

24. Ad N, Henry L, Hunt S, Holmes S, Burton N, et al. (2011) Endoscopic versus direct vision for saphenous vein graft harvesting in coronary artery bypass surgery. J Cardiovasc Surg (Torino) 52: 739-748.

25. Allen KB, Griffith GL, Heimansohn DA, Robison RJ, Matheny RG, et al. (1998) Endoscopic versus traditional saphenous vein harvesting: a prospective, randomized trial. Ann Thorac Surg 66: 26-31.

26. Allen KB, Heimansohn DA, Robison RJ, Schier JJ, Griffith GL, et al. (2000) Risk factors for leg wound complications following endoscopic versus traditional saphenous vein harvesting. Heart Surg Forum 3: 325-330.

27. Allen KB, Heimansohn DA, Robison RJ, Schier JJ, Griffith GL, et al. (2003) Influence of endoscopic versus traditional saphenectomy on event-free survival: five-year follow-up of a prospective randomized trial. Heart Surg Forum 6: E143-145.

28. Andreas M, Wiedemann D, Stasek S, Kampf S, Ehrlich M, et al. (2013) Endoscopic vein harvesting is influenced by patient-related risk factors and may be of specific benefit in female patients. Interact Cardiovasc Thorac Surg 17: $603-607$

29. Andreasen JJ, Nekrasas V, Dethlefsen C (2008) Endoscopic vs open saphenous vein harvest for coronary artery bypass grafting: a prospective randomized trial. Eur J Cardiothorac Surg 34: 384-389.

30. Au WK, Chiu SW, Sun MP, Lam KT, Lin MF, et al. (2008) Improved leg wound healing with endoscopic saphenous vein harvest in coronary artery bypass graft surgery: a prospective randomized study in Asian population. J Card Surg 23: 633-637.
31. Bitondo JM, Daggett WM, Torchiana DF, Akins CW, Hilgenberg AD, et al. (2002) Endoscopic versus open saphenous vein harvest: a comparison of postoperative wound complications. Ann Thorac Surg 73: 523-528.

32. Bonde P, Graham AN, MacGowan SW (2004) Endoscopic vein harvest: advantages and limitations. Ann Thorac Surg 77: 2076-2082.

33. Brat R, Horacek J, Sieja J (2013) Endoscopic vs open saphenous vein harvest for coronary artery bypass grafting: a leg-related morbidity and histological comparison. Biomed Pap Med Fac Univ Palacky Olomouc Czech Repub 157 70-74.

34. Carpino PA, Khabbaz KR, Bojar RM, Rastegar H, Warner KG, et al. (2000) Clinical benefits of endoscopic vein harvesting in patients with risk factors for saphenectomy wound infections undergoing coronary artery bypass grafting. $J$ Thorac Cardiovasc Surg 119: 69-75.

35. Chou NK, Lee ML, Wang SS (2009) Endoscopic vein harvest in elective offpump coronary artery bypass grafting. J Zhejiang Univ Sci B 10: 748-752.

36. Cisowski M, Wites M, Gerber W, Drzewiecka-Gerber A, Bochenek A (2000) Minimally invasive saphenous vein harvesting for coronary artery bypass grafting--comparison of three less invasive methods. Med Sci Monit 6: 735-739.

37. Coppoolse R, Rees W, Krech R, Hufnagel M, Seufert K, et al. (1999) Routine minimal invasive vein harvesting reduces postoperative morbidity in cardiac bypass procedures. Clinical report of 1400 patients. Eur J Cardiothorac Surg 16: 61-66.

38. Crouch JD, O'Hair DP, Keuler JP, Barragry TP, Werner PH, et al. (1999) Open versus endoscopic saphenous vein harvesting: wound complications and vein quality. Ann Thorac Surg 68: 1513-1516.

39. Dangel M, Löwe B, Pfeiffer S, Gulielmos V, Schüler S (1998) [A comparative study of minimal invasive harvesting of vena saphena magna segments] Langenbecks Arch Chir Suppl Kongressbd 115: 1305-1307.

40. Davis Z, Jacobs HK, Zhang M, Thomas C, Castellanos Y (1998) Endoscopic vein harvest for coronary artery bypass grafting: technique and outcomes. $J$ Thorac Cardiovasc Surg 116: 228-235.

41. Fabricius AM, Diegeler A, Doll N, Weidenbach H, Mohr FW (2000) Minimally invasive saphenous vein harvesting techniques: morphology and postoperative outcome. Ann Thorac Surg 70: 473-478.

42. Felisky CD, Paull DL, Hill ME, Hall RA, Ditkoff M, et al. (2002) Endoscopic greater saphenous vein harvesting reduces the morbidity of coronary artery bypass surgery. Am J Surg 183: 576-579.

43. Folliguet T, Severac-Bastide R, Le Bret E, Temkine J, Dibie A, et al. (1999) [Harvesting of an internal saphenous graft for aorto-coronary bypass using video-surgery]. Arch Mal Coeur Vaiss 92: 859-866.

44. Galbraith GF, Pica-Furey W (2000) A retrospective comparative study of open and endoscopic saphenous vein harvesting. J Endovasc Ther 7: 460-468.

45. Grant SW, Grayson AD, Zacharias J, Dalrymple-Hay MJ, Waterworth PD, et al. (2012) What is the impact of endoscopic vein harvesting on clinical outcomes following coronary artery bypass graft surgery? Heart 98: 60-64

46. Hassan A, Yip AM, MacLeod JB, Lutchmedial S, Ouzounian M, et al. (2013) Endoscopic vein harvest is associated with lower rates of leg wound infection at 30 days following cardiac surgery. Can J Cardiol 29: S251.

47. Hayward TZ 3rd, Hey LA, Newman LL, Duhaylongsod FG, Hayward KA, et al. (1999) Endoscopic versus open saphenous vein harvest: the effect on postoperative outcomes. Ann Thorac Surg 68: 2107-2110.

48. Ikram MU, Li WW, Segers P, Kloek JJ, de Mol BA (2010) [Endoscopic veingraft harvesting for coronary bypass grafting: good results in patients at risk for surgical site infection]. Ned Tijdschr Geneeskd 154: A1806.

49. Inderbitzin DT, Reuthebuch O, Winkler B, Melly L, Matt P, et al. (2012) Higher surgical site infection rate after endoscopic vein harvest at the lower leg than at the thigh: a prospective analysis including 1251 patients undergoing CABG. Innovations (Phila) 7: 141-142.

50. Isgro F, Weisse U, Voss B, Kiessling AH, Saggau W (1999) Minimally invasive saphenous vein harvesting: is there an improvement of the results with the endoscopic approach? Eur J Cardiothorac Surg 16 Suppl 2: S58-60.

51. Javidi D, Ladan M, Karaji N, Dastgheib B, Nikzad F, et al. (2008) Endoscopic vein harvesting in CABG surgery - an initial Iranian experience. Iran J Card Surg 2: 7-13. 
Citation: Oddershede L, Andreasen JJ (2014) Endoscopic Vein Harvesting for Coronary Artery Bypass Grafting is Safe and Reduces Postoperative Resource Consumption. J Cardiovasc Dis Diagn 2: 171. doi:10.4172/2329-9517.1000171

52. Kan CD, Luo CY, Yang YJ (1999) Endoscopic saphenous vein harvest decreases leg wound complication in coronary artery bypass grafting patients. J Card Surg 14: 157-162.

53. Kiaii B, Moon BC, Massel D, Langlois Y, Austin TW, et al. (2002) A prospective randomized trial of endoscopic versus conventional harvesting of the saphenous vein in coronary artery bypass surgery. J Thorac Cardiovasc Surg 123: 204-212.

54. Kirmani BH, Barnard JB, Mourad F, Blakeman N, Chetcuti K, et al. (2010) Midterm outcomes for Endoscopic versus Open Vein Harvest: a case control study. J Cardiothorac Surg 5: 44.

55. Krishnamoorthy B, Critchley WR, Glover AT, Nair J, Jones MT, et al. (2012) A randomized study comparing three groups of vein harvesting methods for coronary artery bypass grafting: endoscopic harvest versus standard bridging and open techniques. Interact Cardiovasc Thorac Surg 15: 224-228.

56. Li CY, Lai ST, Yu TJ, Wang JS (1998) Endoscopic vein harvest for coronary artery bypass surgery. Zhonghua Yi Xue Za Zhi (Taipei) 61: 276-280.

57. Lopes RD, Hafley GE, Allen KB, Ferguson TB, Peterson ED, et al. (2009) Endoscopic versus open vein-graft harvesting in coronary-artery bypass surgery. N Engl J Med 361: 235-244.

58. Morris RJ, Butler MT, Samuels LE (1998) Minimally invasive saphenous vein harvesting. Ann Thorac Surg 66: 1026-1028.

59. Nahata SK, Genovesi MH, Torrillo L, Acinapura AJ, Zisbrod Z, et al. (1998) Endoscopic saphenous vein harvesting decreases leg wound infections in CABG patients. Circulation 98: S130.

60. Pagni S, Ulfe EA, Montgomery WD, VanHimbergen DJ, Fisher DJ, et al. (1998) Clinical experience with the video-assisted saphenectomy procedure for coronary bypass operations. Ann Thorac Surg 66: 1626-1631.
61. Perrault LP, Jeanmart H, Bilodeau L, Lespérance J, Tanguay JF, et al. (2004) Early quantitative coronary angiography of saphenous vein grafts for coronary artery bypass grafting harvested by means of open versus endoscopic saphenectomy: a prospective randomized trial. J Thorac Cardiovasc Surg 127 1402-1407.

62. Puskas JD, Wright CE, Miller PK, Anderson TE, Gott JP, et al. (1999) A randomized trial of endoscopic versus open saphenous vein harvest in coronary bypass surgery. Ann Thorac Surg 68: 1509-1512.

63. Schurr UP, Lachat ML, Reuthebuch O, Kadner A, Mäder M, et al. (2002) Endoscopic saphenous vein harvesting for CABG -- a randomized, prospective trial. Thorac Cardiovasc Surg 50: 160-163.

64. Terrini A, Graffigna A, Martinelli L (2000) [A reduction in the invasiveness during surgical revascularization: the harvesting of the great saphenous vein by a video endoscopic technic]. Ital Heart J Suppl 1: 674-678.

65. Wang $H$, Wu $H$, Jiang $H$, Wang Z, Potapov E, et al. (2011) Initial experience with endoscopic saphenous vein harvesting for coronary artery bypass grafting in Chinese patients. Heart Surg Forum 14: E291-296.

66. Yadav R, Sobhun G, Trimlett R, DeSouza A (2012) Endoscopic Vein Harvesting: Short- and Mid-Term Mortality and Morbidity Compared to Open Vein Harvesting. Innovations (Phila) 7: 142.

67. Yun KL, Wu Y, Aharonian V, Mansukhani P, Pfeffer TA, et al. (2005) Randomized trial of endoscopic versus open vein harvest for coronary artery bypass grafting: six-month patency rates. J Thorac Cardiovasc Surg 129: 496-503.

68. Zenati MA, Shroyer AL, Collins JF, Hattler B, Ota T, et al. (2011) Impact of endoscopic versus open saphenous vein harvest technique on late coronary artery bypass grafting patient outcomes in the ROOBY (Randomized On/Off Bypass) Trial. J Thorac Cardiovasc Surg 141: 338-344. 